\title{
The epidemiology of infectious gastroenteritis related reactive arthritis in U.S. military personnel: a case-control study
}

\author{
Jennifer A Curry ${ }^{1}$, Mark S Riddle ${ }^{2}$, Robert P Gormley ${ }^{2}$, David R Tribble ${ }^{1}$, Chad K Porter ${ }^{2 *}$
}

\begin{abstract}
Background: Reactive arthritis (ReA) is a recognized sequela of infectious gastroenteritis (IGE). However, the population-based incidence of IGE-related ReA is poorly defined, and the risk of disease has not previously been characterized in a military population. The intent of this study was to provide estimates of the incidence and morbidity associated with IGE-related ReA in the U.S. military population.
\end{abstract}

Methods: Using active duty US military medical encounter data from the Defense Medical Surveillance System, we conducted a matched case-control study to assess the risk of ReA following IGE. Both specific and nonspecific case definitions were utilized to address ICD-9 coding limitations; these included specific ReA (Reiter's Disease or postdysenteric arthritis) and nonspecific arthritis/arthralgia (N.A.A) (which included several related arthropathy and arthralgia diagnoses). Incidence was estimated using events and the total number of active duty personnel for each year.

Results: 506 cases of specific ReA were identified in active duty personnel between 1999 and 2007. Another 16,365 cases of N.A.A. were identified. Overall incidence was 4.1 (95\% Cl: 3.7, 4.5) and $132.0(95 \% \mathrm{Cl}, 130.0-134.0)$ per 100,000 for specific ReA and N.A.A, respectively. Compared to the youngest age category, the incidence of both outcomes increased 7-fold with a concurrent increase in symptom duration for cases over the age of 40. Specific IGE exposures were documented in $1.4 \%$ of subjects. After adjusting for potential confounders, there was a significant association between IGE and ReA (specific reactive arthritis OR: 4.42, 95\% Cl: 2.24, 8.73; N.A.A OR: 1.76, 95\% Cl: 1.49, 2.07).

Conclusions: Reactive arthritis may be more common in military populations than previously described. The burden of ReA and strong association with antecedent IGE warrants continued IGE prevention efforts.

\section{Background}

Although infectious gastroenteritis (IGE) is typically a short-lived, acute illness, disease morbidity is significant. Incidence rates in travelers have been reported at 29 episodes per 100 person-months, based on self-reported symptoms and cohort studies[1]. Total IGE morbidity is likely underestimated due to unmeasured chronic sequelae, including reactive arthritis $(\operatorname{ReA})[2-8]$. ReA is a systemic inflammatory disorder characterized by an asymmetric, additive, aseptic arthritis triggered by an infection at a distant site. Previously considered a self-

\footnotetext{
* Correspondence: chad.porter@med.navy.mil

${ }^{2}$ Naval Medical Research Center, Silver Spring, Maryland, USA

Full list of author information is available at the end of the article
}

limited disease, the potential of ReA to cause prolonged, recurrent, or erosive disease has increasingly been recognized[2,3,5,7,9-11].

IGE-associated ReA is most commonly described after infection with Campylobacter [11-15], Salmonella [16-19], Shigella[4,20], and Yersinia[21,22]. Other ReA case reports have implicated asymptomatic enteric infections[23], enterotoxigenic E. coli (ETEC)[10,24], Cryptosporidium spp[25,26], Giardia lamblia[27], Strongyloides stercoralis[28], and possibly Schistosoma mansoni[23], and Clostridium difficile[29-33].

Two pseudonyms for ReA exist. Reiter's disease (RD) refers to the classic triad of arthritis, urethritis, and conjunctivitis, while postdysenteric arthritis (PA) refers specifically to IGE-related disease. In recent years, both
() Biomed Central

ㄷ 2010 Curry et al; licensee BioMed Central Ltd. This is an Open Access article distributed under the terms of the Creative Commons Attribution License (http://creativecommons.org/licenses/by/2.0), which permits unrestricted use, distribution, and reproduction in any medium, provided the original work is properly cited. 
subsets of disease have been referred to as reactive arthritis, although the naming convention has not been standardized[2,34]. Current ICD-9 coding includes PA and RD, but not ReA.

Prior studies based on culture-confirmed bacterial disease have estimated incidence rates of 3.1-5.0 per $100,000[35,36]$. However, these estimates do not account for non-bacterial etiologies or uncultured IGE-associated ReA. A Scandinavian study showed a higher incidence (18 per 100,000$)$ based on serologic and/or culturebased evidence of a prior infection[37].

The US military is at high risk of exposure to IGEcausing pathogens during deployment $[1,38,39]$ and may subsequently be at an increased risk of ReA. The considerable health-care associated costs and decreased quality of life associated with ReA and other IGE sequelae could represent an important consideration to further justify efforts aimed at decreasing the incidence of IGE among US military.

\section{Methods}

This was a matched case-control study to evaluate ReA associated with IGE in a US military population. Data were obtained from the Armed Forces Health Surveillance Center (AFHSC) which operates the Defense Medical Surveillance System (DMSS), a database containing medical data on all active duty US military personnel [40]. All records meeting outcome case definitions from 1999 to 2007 were included. These data were linked via social security number to demographic data from the Defense Manpower Data Center (DMDC), and deployment data. Data were compiled into a single dataset, deidentified, and provided to the investigators by AFHSC personnel. The number of active military personnel, stratified by service, year, and age, was obtained through the Defense Medical Epidemiology Database (DMED) [41]. The study protocol was approved by the Naval Medical Research Center and the Uniformed Services University of the Health Sciences Institutional Review Boards in compliance with all applicable Federal regulations governing the protection of human subjects.

\section{Outcome}

The primary outcome of interest was ReA. Cases were identified using ICD-9 codes associated with ReA that met case definitions as described in Table 1. Since there is no ICD-9 code for 'reactive arthritis', and because RD has historically required the presence of cervicitis or urethritis, several nonspecific arthropathy and arthralgia related ICD-9 codes were included. Postdysenteric arthritis and RD cases were combined into a 'specific reactive arthritis' outcome. Cases meeting the nonspecific definition were termed 'nonspecific arthropathy/ arthralgia' (N.A.A). To minimize incorrect or spurious diagnoses, our case definitions required a minimum of two separate ReA-related medical encounters within a 12 month period.

ReA cases with a concurrent diagnosis of chlamydia or gonococcal disease (within 6 months; by ICD-9 code) were excluded. All other ReA cases were included in the analysis. Each case was matched by year of birth, sex, and calendar year to 4 controls with unrelated medical encounters.

The number and duration of ReA-related clinical visits were determined using the number of medical encounters with a ReA-related ICD-9 and time between the first and last ReA-related visit, respectively. When available, the affected site was also recorded (Reiter's disease ICD-9 code 099.3 does not include a sub-code to indicate affected site).

\section{Exposure}

The primary exposure of interest was infectious gastroenteritis (IGE). Prior surveys have indicated that stool cultures are requested in less than $50 \%$ of outpatient visits for acute diarrhea[42]. As such, exposures were evaluated both for specific pathogens, and for nonspecific infectious enteritis as previously described[43]. Exposures were determined by ICD-9 codes for clinical visits within a 6-month window prior to case-presentation or censoring.

\section{Potential confounders}

Demographic variables such as race, rank, marital status, educational level, and branch of service were evaluated as potential confounders. Deployment to an area of high traveler's diarrhea risk within 6 months of censure was also evaluated as a surrogate for IGE. High-risk deployments were defined as Operation Iraqi Freedom, Operation Enduring Freedom, the Persian Gulf, and/or Southwest Asia.

\section{Analysis}

Crude incidence rates were calculated using the number of incident ReA cases, and active duty population figures. Confidence intervals for rates were computed using exact binomial methods. Analysis of change in incidence rates over time was completed using a Poisson regression. A Pearson's Chi-square test was used to compare the proportion of cases receiving care at given time-points after initial diagnosis. The association between ReA, IGE, and potential covariates was assessed using univariate and multivariate conditional logistic regression models. For the multivariate models, a backwards elimination approach was used and variables were dichotomized based on univariate analyses. The variable with the largest p-value was removed, and the model was then re-fit. This process was continued iteratively 
Table 1 Case definitions for primary outcomes

\begin{tabular}{|c|c|c|}
\hline Category & $\begin{array}{l}\text { ICD-9 code } \\
\text { (s) }\end{array}$ & Case Definition \\
\hline Reiter's Disease & $099.3,711.1$ & $\begin{array}{l}\text { Minimum of two medical encounters with Reiter's disease coded within } 12 \text { months } \\
\text {-OR- } \\
\text { One medical encounter with Reiter's disease coded, preceded by at least one encounter with a nonspecific } \\
\text { arthropathy coded within } 12 \text { months }\end{array}$ \\
\hline Postdysenteric arthritis & 711.3 & $\begin{array}{l}\text { Minimum of two medical encounters with postdysenteric arthritis coded within } 12 \text { months } \\
\text {-OR- } \\
\text { One medical encounter with postdysenteric arthritis coded, preceded by at least one encounter with a } \\
\text { nonspecific arthropathy coded within } 12 \text { months }\end{array}$ \\
\hline Specific ReA diagnosis & $\begin{array}{l}\text { 099.3, 711.1, } \\
711.3\end{array}$ & Meets criteria for Reiter's Disease OR postdysenteric arthritis \\
\hline $\begin{array}{l}\text { Nonspecific arthropathy/ } \\
\text { arthalgia }^{a}\end{array}$ & $\begin{array}{l}716.4,716.5 \\
716.6,716.9 \\
719.4\end{array}$ & $\begin{array}{l}\text { Minimum of two medical encounters with a nonspecific arthropathy coded within } 12 \text { months. Subjects } \\
\text { meeting the Reiter's disease or postdysenteric arthritis definitions were excluded. }\end{array}$ \\
\hline
\end{tabular}

a The listed nonspecific arthopathy/arthalgia ICD-9 codes correspond to the following: transient arthropathy (all subgroups), unspecified polyarthropathy or polyarthritis (all subgroups), unspecified monoarthritis (all subgroups), other specified arthropathy (all subgroups), and unspecified arthropathy (all subgroups)

until all variables retained in the models were significant at an alpha $=0.15$. Separate analyses were performed for the specific ReA diagnosis (RD and PA) and the nonspecific diagnosis. Two-tailed statistical significance was evaluated using an alpha of 0.05 . Statistical analyses were performed using SAS v. 8.2 for Windows (SAS Institute, Cary, NC).

\section{Results}

Between 1999 and 2007 a total of 506 subjects met the specific ReA case definition, including 482 with Reiter's disease (RD) and 32 with postdysenteric arthritis (PA). Eight cases met both the RD and PA case definitions. An additional 16,365 cases met the nonspecific arthritis/ arthalgia (N.A.A) case definition. Incidence rates for specific ReA and N.A.A were 4.1 (95\% CI: 3.7, 4.5) and 132.0 (95\% CI: $130.0,134.0)$ per 100,000, respectively. A rising incidence over time of N.A.A was observed ( $\mathrm{p}<$ 0.0001 ), while incidence rates for specific ReA remained stable (Figure 1).

Demographic data for the included study population are shown in Tables 2 and 3. For RD and PA, cases were more commonly deployed to a high risk region in the 6 months pre-censure $(7.5 \%$ and $9.4 \%$, respectively) than controls ( $3.8 \%$ and $3.1 \%$, respectively) $(\mathrm{p}=0.001$ and $\mathrm{p}=0.14$, respectively). The opposite was true for $\mathrm{N}$. A.A, where controls were more likely to have been deployed $(4.7 \%)$ than cases $(2.3 \%)(\mathrm{p}<0.001)$. Only $1.4 \%$ of all cases had an exposure documented within the preceding 6 months, and very few of these indicated pathogen-specific causes. A greater proportion of RD and PA cases had a documented exposure $(3.5 \%$ and $3.1 \%$, respectively), compared to nonspecific $\operatorname{ReA}(1.3 \%)(\mathrm{p}<$ 0.001 and $\mathrm{p}=0.4$, respectively). However, prior IGE was more common in all cases than in their matched controls.
For both specific ReA and N.A.A, incidence rose with increasing age (Beta $=1.04, \mathrm{p}=0.002$ and Beta $=55.68$, $\mathrm{p}=0.006$, respectively). Distribution of cases by age category is shown in Figure 2. Nonspecific arthritis/ arthralgia rates increased nearly 10 -fold over the age spectrum, from 39.8 per 100,000 (95\%CI $36.1-44.0)$ in the $<20$ age group, to 349.7 per 100,000 (95\%CI $339.5-$ $360.2)$ in the $>40$ age group. Similar increases were seen for specific ReA diagnoses, from 0.99 per 100,000 $(95 \%$ CI $0.52-1.82)$ in the $<20$ age group, to 7.09 per $100,000(95 \%$ CI $5.70-8.72)$ in the $>40$ age group.

Unadjusted and adjusted odds ratios (OR) with $95 \%$ confidence intervals $(95 \% \mathrm{CI})$ are shown in Table 4. After controlling for deployment, branch of service, marital status, and rank, ReA cases had higher odds of documented IGE exposure compared to matched controls for both specific ReA (OR: 4.42; 95\% CI: 2.24, 8.73) and N.A.A (OR: 1.76; 95\% CI: 1.49, 2.07).

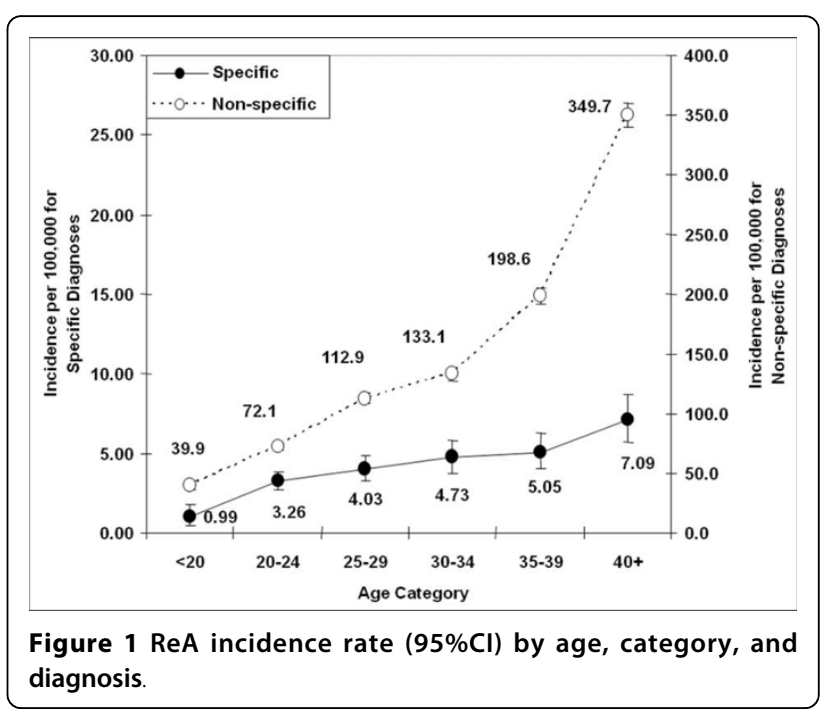


Table 2 Demographic characteristics of US military service members diagnosed with Reiter's disease and postdysenteric arthritis between 1999 and 2007 and their matched controls

\begin{tabular}{|c|c|c|c|c|c|}
\hline Category & Subcategory & $\begin{array}{l}\text { Reiter's Disease } \\
\text { Cases }^{\mathrm{a}}\end{array}$ & $\begin{array}{l}\text { Reiter's Disease } \\
\text { Controls }\end{array}$ & $\begin{array}{c}\text { Postdysenteric Arthritis } \\
\text { Cases }^{\mathrm{a}}\end{array}$ & $\begin{array}{c}\text { Postdysenteric Arthritis } \\
\text { Controls }\end{array}$ \\
\hline $\mathrm{N}$ & & 482 & 1,928 & 32 & 128 \\
\hline Age (mean \pm SD) & & $30.9 \pm 8.1$ & $30.9 \pm 8.1$ & $32.1 \pm 8.61$ & $32.1 \pm 8.61$ \\
\hline \multirow[t]{2}{*}{$\operatorname{Sex}(n ; \%)$} & Male & $436(90.5)$ & $1,744(90.5)$ & $24(75.0)$ & $96(75.0)$ \\
\hline & Female & $46(9.5)$ & $184(9.5)$ & $8(25.0)$ & $32(25.0)$ \\
\hline \multirow[t]{6}{*}{ Race (n; \%) } & Asian & $14(2.9)$ & $106(5.5)$ & $1(3.1)$ & $7(5.4)$ \\
\hline & Black & $57(11.8)$ & $340(17.6)$ & $5(15.6)$ & $26(20.3)$ \\
\hline & Hispanic & $34(7.1)$ & $187(9.7)$ & $2(6.3)$ & $16(12.5)$ \\
\hline & Indian & $6(1.2)$ & $16(0.8)$ & $0(0.0)$ & $1(0.8)$ \\
\hline & White & $356(73.9)$ & $1,235(64.1)$ & $23(71.9)$ & $71(55.5)$ \\
\hline & Other/Unknown & $15(3.1)$ & $44(2.3)$ & $1(3.1)$ & $7(5.5)$ \\
\hline \multirow[t]{3}{*}{ Marital Status (n; \%) } & Single & $171(35.5)$ & $713(37.0)$ & $10(31.3)$ & $55(43.0)$ \\
\hline & Married & $280(58.1)$ & $1,141(59.1)$ & $20(62.5)$ & $68(43.0)$ \\
\hline & Other/Unknown & $31(6.4)$ & $74(3.8)$ & $2(6.3)$ & $5(3.4)$ \\
\hline \multirow[t]{4}{*}{ Service Branch ( $n$; \%) } & Air Force & $142(29.5)$ & $459(23.8)$ & $14(43.8)$ & $37(28.9)$ \\
\hline & Army & $156(32.4)$ & $729(37.8)$ & $11(34.4)$ & $54(42.2)$ \\
\hline & Marine & $59(12.2)$ & $241(12.5)$ & $3(9.4)$ & $14(10.9)$ \\
\hline & Navy & $125(25.9)$ & $499(25.9)$ & $4(12.5)$ & $23(18.0)$ \\
\hline \multirow[t]{3}{*}{$\operatorname{Rank}(\mathrm{n} ; \%)$} & Enlisted & $389(80.7)$ & 1,554 (80.6) & $24(75.0)$ & $94(73.4)$ \\
\hline & Warrant & $9(1.9)$ & $21(1.1)$ & $0(0.0)$ & $3(2.3)$ \\
\hline & Officer & $84(17.4)$ & $353(18.3)$ & $8(25.0)$ & $31(24.2)$ \\
\hline \multirow[t]{5}{*}{ Education level (n; \%) } & High School or equivalent & $310(63.9)$ & $1,240(64.3)$ & $15(46.8)$ & $77(60.2)$ \\
\hline & Some college & $63(13.1)$ & $218(11.3)$ & $7(21.9)$ & $11(8.6)$ \\
\hline & Bachelors & $57(11.8)$ & $265(13.7)$ & $7(21.9)$ & $20(15.6)$ \\
\hline & Post grad & $33(6.8)$ & $152(7.9)$ & $3(9.4)$ & $14(10.9)$ \\
\hline & Unknown & $19(3.9)$ & $53(2.7)$ & $0(0.0)$ & $6(4.7)$ \\
\hline High Risk Deployment ${ }^{b}$ & 6 months & $36(7.5)$ & $74(3.8)$ & $3(9.4)$ & $4(3.1)$ \\
\hline \multirow[t]{3}{*}{$(\mathrm{n} ; \%)$} & 5 months & $31(6.4)$ & $59(3.1)$ & $1(3.1)$ & $4(3.1)$ \\
\hline & 4 months & $22(4.6)$ & $49(2.5)$ & $1(3.1)$ & $2(1.6)$ \\
\hline & 3 months & $15(3.1)$ & $37(1.9)$ & $1(3.1)$ & $1(1.6)$ \\
\hline Documented Infectious & 6 months & $17(3.5)$ & $15(0.8)$ & $1(3.1)$ & $2(1.6)$ \\
\hline \multirow[t]{3}{*}{ Gastroenteritis $(n ; \%)$} & 5 months & $15(3.1)$ & $11(0.6)$ & $1(3.1)$ & $2(1.6)$ \\
\hline & 4 months & $14(2.9)$ & $10(0.5)$ & $1(3.1)$ & $0(0.0)$ \\
\hline & 3 months & $13(2.7)$ & $9(0.5)$ & $1(3.1)$ & $0(0.0)$ \\
\hline
\end{tabular}

Backround active duty population rates: $85 \%$ male; 69\%white/19\%black/12\%other; 35\%Army/26\%AirForce/26\%Navy/13\%Marine

a Eight cases overlap case definitions for both Reiter's disease and postdysenteric arthritis

${ }^{b}$ Deployment to a region at high risk for travelers' diarrhea (Iraq, Afghanistan, Persian Gulf or Southwest Asia) within the indicated number of months prior to ReA diagnosis (cases) or censoring (controls)

Deployment to a high risk area was associated with an increased risk of specific ReA (OR: 2.07; 95\% CI: 1.36, 3.15). However, it was protective against N.A.A (OR: 0.47; 95\% CI: 0.41, 0.51). Army service (compared to other branches of service) was associated with an increased risk of N.A.A (OR 1.54; 95\%CI: 1.49, 1.60). This association was reversed for specific ReA (OR: 0.77; 95\% CI: $0.62,0.94)$. Odds ratios for marriage and enlisted status in the N.A.A group were 1.21 (95\% CI: $1.16,1.27)$ and 1.66 (95\% CI: $1.58,1.74)$, respectively. Neither marital status nor rank were associated with a change in specific ReA risk.
Duration of ReA symptoms was prolonged after initial diagnosis. Among specific ReA cases that remained on active duty, 35.5\% (89/251) were still receiving ReArelated medical care for a minimum of 2 years after initial presentation (Figure 3). This proportion was lower $(\mathrm{p}<0.001)$ for the N.A.A cases $(1,019 / 6,380$; $16.0 \%)$. Increased duration of care was associated with increasing age for both the specific ReA (Cochran Armitage Trend $\mathrm{p}<0.001)$ and non-specific $(\mathrm{p}<0.001)$ arthropathy/arthralgia outcomes with the following proportion receiving care at least 2 years after initial diagnosis (specific ReA: $\leq 25: 13.5 \%$, $>25$ to $<35: 29.2 \%$, 
Table 3 Demographic characteristics of US military service members diagnosed with nonspecific arthropathy/ arthralgia between 1999 and 2007 and their matched controls

\begin{tabular}{|c|c|c|c|}
\hline Category & Subcategory & $\begin{array}{c}\text { Nonspecific } \\
\text { Arthralgia/ } \\
\text { Arthropathy Cases }\end{array}$ & $\begin{array}{c}\text { Nonspecific } \\
\text { Arthralgia/ } \\
\text { Arthropathy Controls }\end{array}$ \\
\hline $\mathrm{N}$ & & 16,365 & 65,422 \\
\hline Age $($ mean $\pm S D)$ & & $33.4 \pm 8.8$ & $33.4 \pm 8.8$ \\
\hline \multirow[t]{2}{*}{$\operatorname{Sex}^{a}(n ; \%)$} & Male & $12,979(79.3)$ & $51,895(79.3)$ \\
\hline & Female & $3,385(20.7)$ & $13,523(20.7)$ \\
\hline \multirow[t]{6}{*}{ Race $(n ; \%)$} & Asian & $620(3.8)$ & $2914(4.5)$ \\
\hline & Black & $3,687(22.5)$ & $12,256(18.7)$ \\
\hline & Hispanic & $1,445(8.8)$ & $6,290(9.6)$ \\
\hline & Indian & $250(1.5)$ & $922(1.4)$ \\
\hline & White & $9,920(60.6)$ & $41,210(63.0)$ \\
\hline & Other/Unknown & $443(2.7)$ & $1,830(2.8)$ \\
\hline \multirow[t]{3}{*}{ Marital Status (n; \%) } & Single & $4,407(26.9)$ & $20,536(31.4)$ \\
\hline & Married & $10,904(66.6)$ & $41,398(63.3)$ \\
\hline & Other/Unknown & $1,054(6.4)$ & $3488(5.3)$ \\
\hline \multirow[t]{4}{*}{ Service Branch (n; \%) } & Air Force & 3,671 (22.4) & $17,089(26.1)$ \\
\hline & Army & $7,865(48.1)$ & $24,628(37.6)$ \\
\hline & Marine & $1,016(6.2)$ & $6,350(9.7)$ \\
\hline & Navy & $3,813(23.3)$ & $17,355(26.5)$ \\
\hline \multirow[t]{3}{*}{$\operatorname{Rank}^{\mathbf{a}}(\mathrm{n} ; \%)$} & Enlisted & $13,782(84.2)$ & $50,541(77.2)$ \\
\hline & Warrant & $312(1.9)$ & $1,106(1.7)$ \\
\hline & Officer & 2,271 (13.9) & $13,775(21.1)$ \\
\hline \multirow[t]{5}{*}{ Education level ( $n$; \%) } & High School or equivalent & $10,781(65.9)$ & 39,195 (59.9) \\
\hline & Some college & $2,023(12.4)$ & $7,563(11.6)$ \\
\hline & Bachelors & $1,835(11.2)$ & $9,511(14.5)$ \\
\hline & Post grad & $1,330(8.1)$ & $7,204(11.0)$ \\
\hline & Unknown & $396(2.4)$ & $1,949(3.0)$ \\
\hline High Risk Deployment $^{\text {b }}$ & 6 months & $374(2.3)$ & $3,097(4.7)$ \\
\hline \multirow[t]{3}{*}{$(n ; \%)$} & 5 months & $280(1.7)$ & $2,571(3.9)$ \\
\hline & 4 months & $182(1.1)$ & $2,077(3.2)$ \\
\hline & 3 months & $110(0.7)$ & $1,568(2.4)$ \\
\hline Documented Infectious & 6 months & $211(1.3)$ & $472(0.7)$ \\
\hline \multirow[t]{3}{*}{ Gastroenteritis $(n ; \%)$} & 5 months & $181(1.1)$ & $401(0.6)$ \\
\hline & 4 months & $154(0.9)$ & $332(0.5)$ \\
\hline & 3 months & $123(0.8)$ & $256(0.4)$ \\
\hline
\end{tabular}

Backround active duty population rates: $85 \%$ male; 69\%white/19\%black/12\%other; 35\%Army/26\%AirForce/26\%Navy/13\%Marine

a Missing values: Sex (1 case, 4 controls), Rank (1 control)

${ }^{\mathrm{b}}$ Deployment to a region at high risk for travelers' diarrhea (Iraq, Afghanistan, Persian Gulf or Southwest Asia) within the indicated number of months prior to ReA diagnosis (cases) or censoring (controls)

$\geq 35: 57.3 \%$; N.A.A: $\leq 25: 12.7 \%,>25$ to $<35: 28.5 \%$, $\geq 35$ : $58.9 \%)$. Males had significantly higher proportion receiving care for specific $\operatorname{ReA}$ at 2 years than did females (38.7\% vs $7.7 \%$, respectively) (Pearson ChiSquare $p=0.002)$. This gender effect was not observed for the N.A.A outcome.

An analysis of the affected site showed that the majority $(47 \%)$ of cases had no indicated joint. Although categories are not mutually exclusive, RD (limited to ICD-9 code 711.1 ) predominately affected the knee $(9.8 \%)$ or multiple joints (17.1\%). The hand (15.6\%), knee (15.6\%), and multiple joints (28.1\%) were the most commonly affected in PA. N.A.A most commonly affected the shoulder (22.6\%), knee (15.3\%), and ankle/foot (13.0\%), with only $2.4 \%$ coded as multiple joints.

\section{Discussion}

We found an incidence of 4.1 per 100,000 persons for specific ReA in an active duty population. Prior publications have reported similar population incidence rates of 3-5 per 100,000, for ReA with culture confirmed antecedent bacterial IGE[35,36]. However, as clinical 


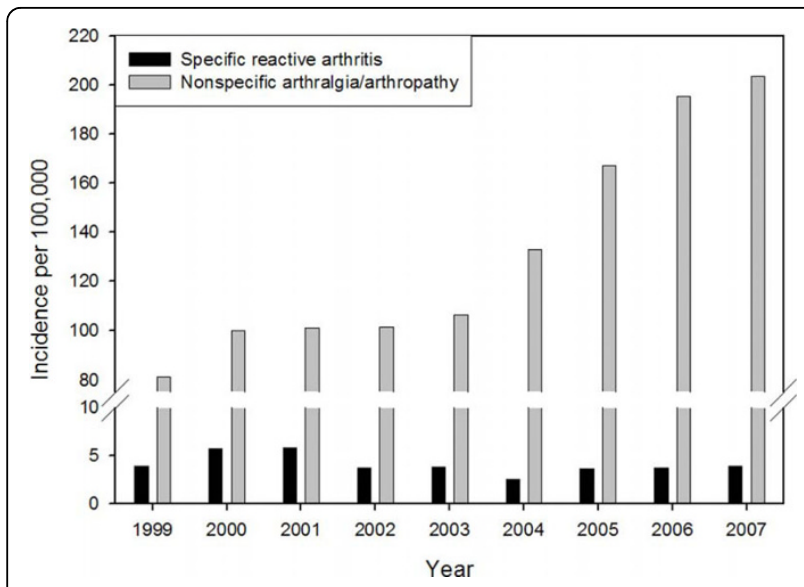

Figure 2 Incidence of reactive arthritis and nonspecific arthropathy/arthralgia in active US military personnel 1999 to 2007.

recognition of antecedent infection is required for the specific diagnoses, both the incident rate we report and prior published rates for specific ReA likely underestimate the true incidence of IGE-associated ReA.

Prior studies have reported undifferentiated arthritis in an attempt to describe cases that do not meet the full diagnostic criteria for RD or PA. Schillerup et al. reported an incidence of 41 per 100,000 for undifferentiated inflammatory arthritis[44], and Fendler et al. described a ReA case series in which $59 \%$ of patients presented with a undifferentiated oligoarthritis[45]. Similarly, we used a N.A.A case definition and found an incidence of 132 per 100,000. Our N.A.A. case definition is overly sensitive due to limitations associated with the use of ICD-9 codes. It is very possible that a

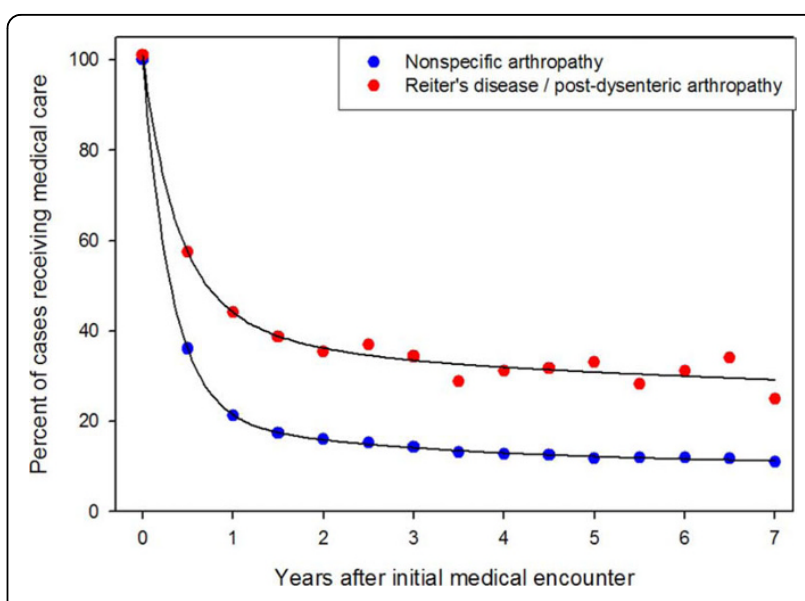

Figure 3 Duration of reactive arthritis-associated medical care in active US military personnel 1999 to 2007.

proportion of our N.A.A cases are somehow different than the specific ReA cases. However, our description of these cases illustrate an upper bound to the incidence of disease to be used in conjunction with the lower bound obtained from the highly restrictive postinfectious gastroenteritis and Reiter's disease case definitions. We suspect the large difference in incidence rates indicate there is a lack of clinical recognition of the reactive nature of at least some arthritis/arthropathy cases. Of note, we found an increasing incidence of N.A.A cases from 2002 to 2007 with an unknown etiology. The impact of deployment tempo during this time frame on N.A.A incidence could not be determined, as only data on deployment to certain high-risk areas was obtained.

Table 4 Unadjusted and adjusted ${ }^{a}$ odds ratios (95\% confidence intervals) for exposure variables and included covariates from a conditional logistic regression model evaluating the risk of specific reactive arthritis and nonspecific arthralgia/arthropathy among active duty US military personnel from 1999 to 2007

\begin{tabular}{llcc}
\hline Model & Variable & All Specific ReA & Nonspecific Arthralgia/Arthropathy \\
\hline Univariate & Prior exposure $^{b}$ & $4.50(2.30,8.82)$ & $1.80(1.53,2.12)$ \\
& High risk deployment $^{c}$ & $2.12(1.40,3.21)$ & $0.47(0.42,0.52)$ \\
& Army service & $0.77(0.63,0.95)$ & $1.54(1.48,1.59)$ \\
& Married & $0.96(0.76,1.22)$ & $1.22(1.17,1.27)$ \\
& Non-white & $0.63(0.50,0.78)$ & $1.11(1.07,1.15)$ \\
Multivariate & Enlisted rank & $1.04(0.79,1.37)$ & $1.68(1.60,1.76)$ \\
& Prior exposure $^{b}$ & $4.42(2.24,8.73)$ & $1.76(1.49,2.07)$ \\
& High risk deployment $^{c}$ & $2.07(1.36,3.15)$ & $0.46(0.41,0.51)$ \\
& Army service & $0.77(0.62,0.94)$ & $1.54(1.49,1.60)$ \\
& Married & $0.97(0.76,1.23)$ & $1.21(1.16,1.27)$ \\
\hline
\end{tabular}

\footnotetext{
${ }^{a}$ Adjusted for all covariates retained in the final model (prior exposure, high risk deployment, Army service, married, non-white and enlisted rank)

${ }^{b}$ Defined as an infectious diarrhea diagnosis six months prior to ReA diagnosis (cases) or censoring (controls)

' Defined as deployment to a region at high risk for travelers' diarrhea (Iraq, Afghanistan, Persian Gulf or Southwest Asia) six months prior to ReA diagnosis (cases) or censoring (controls)
} 
The incidence of both specific ReA and N.A.A increased with age. Published descriptions of age in ReA indicate most cases occur in a young population, generally less than 40 years of age[2,23]. This description likely stems from the earliest case reports of ReA, which largely consisted of STD-related cases. We found no prior publications reporting an increasing incidence with age. Further evaluation of the incidence of ReA in an older population would be worthwhile; however our use of an active duty study population limits our ability to do so.

As expected, we found increased odds of prior IGE in ReA cases compared to matched controls, despite the low rate of documented antecedent gastroenteritis. After controlling for covariates, the OR for specific ReA was 4.42 (95\% CI: 2.24, 8.73). The effect was smaller in the N.A.A group (OR: 1.76, 95\% CI: 1.49, 2.07), though it remained statistically significant. Our actual number of documented cases of IGE was very low; however relying on medical records for documentation of IGE severely underestimates the true incidence[42]. A prior population-based survey indicated less than a quarter of those with acute diarrheal illness seek medical care[46]. This is clearly evident in the paucity of documented IGE exposures in our cases diagnosed with RD and PA, both of which require a clinical recognition of antecedent GI disease.

Our cases are not strictly limited to IGE-related ReA. While we excluded ICD-9 documented Chlamydia and gonococcal infections, our methods potentially misses both asymptomatic chlamydial infections and STI cases diagnosed outside of military data catchment (such as through a public health department). However, IGE related disease likely comprises a large proportion of all reactive arthritis cases, as has been reported previously[37].

We assessed the effect of deployment to high traveler's diarrhea risk regions as a potential surrogate for IGE, due to incomplete data capture in a deployed population. We found an increased odds of prior deployment in those with specific ReA diagnoses. Conversely, there was a protective effect of deployment for the N.A.A diagnoses. The etiology of this relative difference is unclear, but the unique difficulties in capture of deployment related illness and injury data may account for the qualitative shift in the effect estimate. More severe injuries may be preferentially captured as those patients reach higher levels of care where integrated electronic medical systems are more prevalent. Additionally, stress injuries such as tendonitis, trauma, etc are commonly expected when deployed. Patients may be given one of these more common diagnoses, rather than one of the nonspecific codes used in our N.A.A. case definition. Finally, military members with underlying medical illness may not be deployed resulting in a type of "healthy worker" effect which might also explain the lower rate of diagnoses in deployed personnel.

Inherent difference between the specific ReA and N.A. A group could account for directional differences in some effect estimates noted above. This is supported by the difference in concurrent diagnoses for the two case definitions. Specifically, approximately $13 \%$ of the N.A.A cases were seen for physical therapy, $4 \%$ for lumbago, and $3 \%$ for aftercare following surgery. None of these co-morbid diagnoses were among the top 20 for the specific ReA cases. Interestingly, functional gastrointestinal diagnoses were prevalent in both groups (data not shown).

Although the original reports of ReA indicated a selflimited disease, recent publications have described chronic disease in up to half of cases, especially in the presence of HLA-B27[9,34,47]. Our data supports the idea of a more chronic disease, especially among patients over the age of 35 . While we were unable to assess the symptoms associated with a ReA-related medical encounter, or HLA-B27 status, ReA continued to be commonly coded as a primary diagnosis up to 7 years after the initial medical encounter. The chronicity of this disease has not been well recognized by clinicians. However, like the functional gastrointestinal postinfectious disorders, the morbidity associated with ReA needs to be considered by providers and policy makers when assessing the impact associated with deployment of countermeasures, in order to mitigate the effects of acute enteric infections during deployment.

The U.S. active duty military population was used as the study population. There are several unique qualities of this population that should be considered when comparing our findings to the general population. The military population is younger (the average age is roughly 28 ) and generally physically fit, yet extensive physical stressors likely increase the number of musculoskeletal injuries in this population. Military members may travel extensively to underdeveloped areas of the world, placing them at increased risk for IGE exposures. In addition, as there is a direct link between health and duty status, deployment eligibility, and disability claim eligibility, members may have additional ICD-9 coded visits to address the administrative aspects of health issues.

Utilization of a medical encounter database for epidemiologic studies carries an intrinsic risk of misclassification or systemic biases, in addition to those described specifically above. Multiple studies have demonstrated inaccuracies in ICD-9 coding[48-50]. As described in previous publications, we required multiple medical encounters for the same diagnosis in an attempt to minimize case misclassification[43,51]. 


\section{Conclusion}

In summary, we found that ReA was more prevalent than previously recognized in the U.S. active duty military population, especially when non-specific ReA cases were considered. This represents a significant burden on the military healthcare system and may be an important medical condition in returning veterans. Due to the strong association between IGE and ReA as well as other post-infectious sequelae, and the high risk of travelers diarrhea among deployed US service members, efforts aimed at minimizing IGE incidence in DoD personnel are warranted and support enhancement of current primary prevention strategies and development of novel solutions.

\section{Author details}

'Uniformed Services University of the Health Sciences, Bethesda, Maryland, USA. ${ }^{2}$ Naval Medical Research Center, Silver Spring, Maryland, USA.

\section{Authors' contributions}

$J C$ assisted with the statistical analysis and drafted the manuscript. RG conceived of the study and participated in its design. MR participated in the study design, assisted in coordination of the study, and helped draft the manuscript. DT participated in the study design and helped draft the manuscript. CP participated in the study design, assisted in coordination of the study, performed the statistical analysis, and helped draft the manuscript. All authors read and approved the final manuscript.

\section{Competing interests}

The authors declare that they have no competing interests.

Authors are employees of the U.S. Government and military service members. This work was prepared as part of official duties. Title 17 U.S.C. $\$ 105$ provides that 'Copyright protection under this title is not available for any work of the United States Government.' Title 17 U.S.C. §101 defines a U. S. Government work as a work prepared by a military service member or employee of the U.S. Government as part of that person's official duties. The opinions and assertions herein should not be construed as official or representing the views of the Department of the Navy, Department of the Army, the Department of Defense, or the US Government. This is a US Government work. There are no restrictions on its use.

Received: 1 June 2010 Accepted: 13 September 2010

Published: 13 September 2010

\section{References}

1. Riddle MS, Sanders JW, Putnam SD, Tribble DR: Incidence, Etiology, and Impact of Diarrhea among long-term travelers (US Military and Similar Populations): A Systematic Review. Am J Trop Med Hyg 2006, 74:891-900.

2. Hamdulay SS, Glynne SJ, Keat A: When is arthritis reactive? Postgraduate Medicine Journal 2006, 82:446-453.

3. Hawkes J: Clinical and diagnostic features of Reiter's disease: a follow-up study of 39 patients. New Zealand Medical Journal 1973, 78:353.

4. Hannu T, Mattila L, Siitonen A, Leirisalo-Repo M: Reactive arthritis attributable to Shigella infection: a clinical and epidemiological nationwide study. Ann Rheum Dis 2005, 64:594-598.

5. Marks J, Holt J: The natural history of Reiter's disease - 21 years of observations. Quarterly Journal of Medicine 1986, New Series 60:685-697.

6. Paronen I: Reiter's disease: a study of $\mathbf{3 4 4}$ cases observed in Finland. Acta Med Scand 1948, 212:1-112.

7. Sairanen E, Paronen I, Mahonen K: Reiter's Syndrome: A Follow-up Study. Acta Med Scand 1969, 185:57-63.

8. Weinberger $H$, Ropes M, Kulka J, Bauer W: Reiter's syndrome, clinical and pathologic observations: a long term study of 16 cases. Medicine (Baltimore) 1962, 41.

9. Leirisalo M, Skylv G, Kousa M, Voipio-Pulkki L-M, Suoranta H, Nissila M, Hvidman L, Nielsen ED, Svejgaard A, Tiilkainen A, Laitinen O: Follow-up study on patietns Reiter's disease and reactive arthritis, with special reference to HLA-B27. Arthritis \& Rheumatism 1982, 25:249-259.

10. Garg AX, Pope JE, Thiessen-Philbrook H, Clark WF, Ouimet J: Arthritis risk after acute bacterial gastroenteritis. Rheumatology (Oxford) 2008, 47:200-204.

11. Bremell T, Bjelle A, Svedhem A: Rheumatic symptoms following an outbreak of campylobacter enteritis: a five year follow up. Ann Rheum Dis 1991, 50:934-938.

12. Eastmond C, Rennie JN, Reid T: An outbreak of Campylobacter enteritis a rheumatological followup survey. journal of Rheumatology 1983, 10:107-108.

13. van de Putte $L B$, Berden J, Boerbooms M: Reactive arthritis after Campylobacter jejuni enteritis. Journal of Rheumatology 1980, 7:531-535.

14. Hannu T, Mattila L, Rautelin H, Pelkonen P, Lahdenne P, Siitonen A, Leirisalo-Repo M: Campylobacter-triggered reactive arthritis: a population-based study. Rheumatology 2002, 41:312-318.

15. Pope JE, Krizova A, Garg AX, Thiessen-Philbrook H, Ouimet JM: Campylobacter Reactive Arthritis: A Systematic Review. Seminars in Arthritis and Rheumatism 2007, 37:48-55.

16. Locht $H$, Kihlstrom $E$, Lindstrom F: Reactive arthritis after Salmonella among medical doctors - study of an outbreak. Journal of Rheumatology 1993, 20:845-848.

17. Inman RD, Johnston ME, Hodge M, Falk J, Helewa A: Postdysenteric Reactive Arthritis. Arthritis \& Rheumatism 1988, 31:1377-1383.

18. Dworkin MS, Shoemaker PC, Goldoft MJ, Kobayashi JM: Reactive Arthritis and Reiter's Syndrome Following an Outbreak of Gastroenteritis Caused by Salmonella enteritidis. Clinical Infectious Diseases 2001, 33:1010-1014.

19. Hannu T, Mattila L, Siitonen A, Leirisalo-Repo M: Reactive arthritis following an outbreak of Salmonella typhimurium phage type 193 infection. Ann Rheum Dis 2002, 61:264-266.

20. Noer HR: An "Experimental" Epidemic of Reiter's Syndrome. The Journal of the American Medical Association 1966, 197:693-698.

21. Tertti R, Granfors K, Lehtonen O, Mertsola J, Makela A, Toivanen A: An outbreak of Yersinia pseudotuberculosis infection. The Journal of Infectious Diseases 1984, 149:245-250.

22. Hannu T, Mattila L, Nuorti JP, Ruutu P, Mikkola J, Siitonen A, Leirisalo-Repo M: Reactive arthritis after an outbreak of Yersinia pseudotuberculosis serotype O:3 infection. Ann Rheum Dis 2003, 62:866-869.

23. Penn H, Keat A: Post-infective arthritis. Medicine 2006, 34:413-416.

24. Locht H, Krogfelt KA: Comparison of rheumatological and gastrointestinal symptoms after infection with Campylobacter jejuni/coli and enterotoxigenic Escherichia coli. Ann Rheum Dis 2002, 61:448-452.

25. Cron R, Sherry D: Reiter's syndrome associated with cryptosporidial gastroenteritis. Journal of Rheumatology 1995, 22:1962-1963.

26. Shepherd RC, Smail PJ, Sinha GP: Reactive arthritis complicating cryptosporidial infection. Arch Dis Child 1989, 64:743-744.

27. Carlson DW, Finger DR: Beaver Fever arthritis. J Clin Rheumatol 2004, 10:86-88.

28. Richter J, Muller-Stover I, Strothmeyer H, Gobels K, Schmitt M, Haussinger D: Arthritis associated with Strongyloides stercoralis infection in HLA B-27positive African. Parasitol Res 2006, 99:706-707.

29. Löffler HA, Pron B, Mouy R, Wulffraat NM, Prieur A-M: Clostridium difficileassociated reactive arthritis in two children. Joint Bone Spine 2004, 71:60-62.

30. Birnbaum J, Bartlett JG, Gelber AC: Clostridium difficile: an underrecognized cause of reactive arthritis? Clinical Rheumatology 2008, 27:253-255.

31. Putterman $C$, Rubinow A: Reactive arthritis associated with Clostridium difficile pseudomembranous colitis. Seminars in Arthritis and Rheumatism 1993, 22:420-426.

32. Hayward R, Wensel R, Kibsey P: Relapsing Clostridium difficile colitis and Reiter's syndrome. The American Journal of Gastroenterology 1990, 85:752-756.

33. Söderlin MK, Alasaarela E, Hakala M: Reactive Arthritis Induced by Clostridium Difficile Enteritis as a Complication of Helicobacter Pylori Eradication. Clinical Rheumatology 1999, 18:337-338.

34. Leirisalo-Repo M: Reactive arthritis. Scandinavian Journal of Rheumatology 2005, 34:251-259.

35. Townes JM, Doedhar AA, Laine ES, Smith K, Krug HE, Barkhulzen A, Thompson M, Cieslak R, Sobel J: Reactive arthritis following culture 
confirmed infections with bacterial enteric pathogens in Minnesota and Oregon: a population based study. Ann Rheum Dis 2008.

36. Kvien TK, Glennas A, Melby K, Granfors K, Andrup O, Karstensen B, Thoen JE: Reactive arthritis: incidence, triggering agents and clinical presentation. J Rheumatol 1994, 21:115-122.

37. Soderlin MK, Borjesson O, Kautiainen H, Skogh T, Leirisalo-Repo M: Annual incidence of inflammatory joint diseases in a population based study in southern Sweden. Ann Rheum Dis 2002, 61:911-915.

38. Putnam SD, Sanders JW, Frenck RW, Monteville M, Riddle MS, Rockabrand DM, Sharp TW, Frankart C, Tribble DR: Self-Reported Description of Diarrhea Among Military Populations in Operations Iraqi Freedom and Enduring Freedom. Journal of Travel Medicine 2006, 13:92-99.

39. Sanders JW, Putnam SD, Riddle MS, Tribble DR: Military importance of diarrhea: lessons from the Middle East. Curr Opin Gastroenterol 2005, 21:9-14.

40. Rubertone MV, Brundage JF: The Defense Medical Surveillance System and the Department of Defense Serum Repository: Glimpses of the Future of Public Health Surveillance. American Journal of Public Health 2002, 92:1900-1904.

41. Armed Forced Health Surveillance Center: Defense Medical Epidemiology Database. [http://www.afhsc.mil/aboutDmed].

42. Hennessy TW, Marcus R, Deneen V, Reddy S, Vugia D, Townes J, Bardsley M, Swerdlow D, Angulo FJ: Survey of Physician Diagnostic Practices for Patients with Acute Diarrhea: Clinical and Public Health Implications. Clinical Infectious Diseases 2004, 38:S203-S211.

43. Porter CK, Tribble DR, Aliaga PA, Halvorson HA, Riddle MS: Infectious gastroenteritis and risk of developing inflammatory bowel disease. Gastroenterology 2008, 135:781-786.

44. Schiellerup P, Krogfelt KA, Locht H: A comparison of self-reported joint symptoms following infection with different enteric pathogens: effect of HLA-B27. J Rheumatol 2008, 35:480-487.

45. Fendler C, Laitko S, Sorensen H, Gripenberg-Lerche C, Groh A, Uksila J, Granfors K, Braun J, Sieper J: Frequency of triggering bacteria in patients with reactive arthritis and undifferentiated oligoarthritis and the relative importance of the tests used for diagnosis. Annals of the Rheumatic Diseases 2001, 60:337.

46. Imhoff B, Morse D, Shiferaw B, Hawkins M, Vugia D, Lance-Parker S, Hadler J, Medus C, Kennedy M, Moore MR, Van Gilder T: Burden of SelfReported Acute Diarrheal Illness in FoodNet Surveillance Areas, 19981999. Clinical Infectious Diseases 2004, 38:S219-S226.

47. Michet CJ, Machado EB, Ballard DJ, McKenna CH: Epidemiology of Reiter's syndrome in Rochester, Minnesota: 1950-1980. Arthritis Rheum 1988, 31:428-431.

48. Benesch C, Witter DM Jr, Wilder AL, Duncan PW, Samsa GP, Matchar DB: Inaccuracy of the International Classification of Diseases (ICD-9-CM) in identifying the diagnosis of ischemic cerebrovascular disease. Neurology 1997, 49:660-664.

49. Miller ML, Wang MC: Accuracy of ICD-9-CM coding of cervical spine fractures: implications for research using administrative databases. Annu Proc Assoc Adv Automot Med 2008, 52:101-105.

50. Malik A, Dinnella JE, Kwoh CK, Schumacher HR: Poor Validation of Medical Record ICD-9 Diagnoses of Gout in a Veterans Affairs Database. J Rheumatol 2009.

51. Skinner KM, Miller DR, Lincoln E, Lee A, Kazis LE: Concordance between respondent self-reports and medical records for chronic conditions: experience from the Veterans Health Study. J Ambul Care Manage 2005, 28:102-110.

\section{Pre-publication history}

The pre-publication history for this paper can be accessed here: http://www.biomedcentral.com/1471-2334/10/266/prepub

\section{doi:10.1186/1471-2334-10-266}

Cite this article as: Curry et al:: The epidemiology of infectious gastroenteritis related reactive arthritis in U.S. military personnel: a case-control study. BMC Infectious Diseases 2010 10:266.

\section{Submit your next manuscript to BioMed Central and take full advantage of:}

- Convenient online submission

- Thorough peer review

- No space constraints or color figure charges

- Immediate publication on acceptance

- Inclusion in PubMed, CAS, Scopus and Google Scholar

- Research which is freely available for redistribution

Submit your manuscript at www.biomedcentral.com/submit
Ciomed Central 